\title{
Antagonistic interactions between Aureobasidium pullulans and Fusarium culmorum, a fungal pathogen of winter wheat
}

\author{
Urszula Wachowska $\cdot$ Katarzyna Głowacka
}

Received: 23 December 2013/ Accepted: 19 June 2014/Published online: 19 July 2014

(C) The Author(s) 2014. This article is published with open access at Springerlink.com

\begin{abstract}
The effect of the biological control agent Aureobasidium pullulans (de Bary) G. Arnaud on the development of Fusarium head blight (FHB) on winter wheat and kernel contamination with fungi of the genera Fusarium, Acremonium, Cladosporium and Penicillium was analyzed in a greenhouse experiment. Scanning electron microscopy was used to evaluate the distribution of $A$. pullulans cells and aggregates on wheat kernels, infection structures of Fusarium culmorum (W.G. Smith) Sacc and the antagonist-pathogen interactions. Biological control with A. pullulans reduced FHB severity by $21.67 \%$ and improved grain filling by $5.02 \%$, compared with the control treatment. The survival of A. pullulans was good (to 31 cells per kernel), in particular on the surface and in the crease of kernels, including in pathogen-inoculated wheat plants. A. pullulans cells firmly adhered to $F$. culmorum hyphae, and damaged them. In most cases, autochthonous communities of filamentous fungi of
\end{abstract}

Handling Editor: Choong-Min Ryu

U. Wachowska ( $\square)$

Department of Phytopathology and Entomology,

University of Warmia and Mazury in Olsztyn,

Prawocheńskiego 17, 10-720 Olsztyn, Poland

e-mail: urszula.wachowska@uwm.edu.pl

K. Głowacka

Department of Plant Physiology, Genetics and

Biotechnology, University of Warmia and Mazury in

Olsztyn, Oczapowskiego 1A, 10-720 Olsztyn, Poland the genera Acremonium and Penicillium developed at a slower rate after kernel inoculation with the pathogen.

Keywords Aureobasidium pullulans $\cdot$ Fusarium culmorum - Infection structures - Wheat grain Scanning electron microscopy

\section{Introduction}

Aureobasidium pullulans (de Bary) G. Arnaud is a saprotrophic fungal species commonly found in various environments, such as the leaves of crop plants (Grube et al. 2011), cereal grains (Wachowska et al. 2013), fruits (Tournas and Uppal Memon 2009), living quarters (Prasongsuk et al. 2005), food products (Berghofer et al. 2003) and animal feeds (Olstrope et al. 2010). The species is characterized by high morphological plasticity, and Zalar et al. (2008) divided $A$. pullulans strains into six morphologically and genetically different groups. A. pullulans is known for its biotechnological significance as a producer of the biodegradable extracellular polysaccharide (EPS) pullulan (poly-alpha-1,6-maltotriose), which is used in food production (Kuan-Chen et al. 2011; Donot et al. 2012). The biotechnological potential of A. pullulans is also associated with its high enzymatic activity. Depending on temperature, type of fermentation, carbon source, $\mathrm{pH}$ and water availability, the isolates 
of A. pullulans produce endoglucanase, xylanase, beta-glucosidase (Leite et al. 2008), polygalacturonases (Stratilová et al. 2006), amylase (Li et al. 2007; Manitchotpisit et al. 2011) and chitinases (endochtinase, chitobiosidase) and beta-1,3-glucanase that is produced in culture and apple wounds (Castoria et al. 2001). The enzymes produced by A. pullulans are involved in mode of action of this microrganism and play a key role in the biological control of plant diseases, suppressing the growth of phytopathogens. A. pullulans has been found effective against Botrytis cinerea Pers, Penicillium expansum Link, Rhizopus stolonifer (Ehrenb.) Vuill and Aspergillus niger Tiegh on table grapes (Castoria et al. 2001), and the ochratoxigenic Aspergillus carbonarius (Bainier) Thom. on table grapes and strawberry (Lima et al. 1997; Castoria et al. 2001; De Felice et al. 2008; De Curtis et al. 2012b), against B. cinerea and $P$. expansum on apples (Castoria et al. 2001; Ippolito et al. 2000; Mounir et al. 2007), against three species of the genus Monilinia on stone fruit (Mari et al. 2012). De Felice et al. (2008) observed for the first time that three strains of $A$. pullulans were the effective biocontrol agents in reducing both severity of Aspergillus rots in the vineyard and ochratoxin A (OTA) accumulation in wine grapes. In this regard these strains were shown to degrade OTA to OTA (de Felice et al. 2008; De Curtis et al. 2012b). Moreover, the strain LS30 of $A$. pullulans significantly reduced powdery mildew on winter wheat under field conditions (De Curtis et al. 2012a). Lytic enzymes produced by yeasts destroy the cell walls of pathogenic fungi. Candida guilliermondii (Castell.) Langeron \& Guerr and Candida oleophila Montrocher have been found to degrade the cell walls of $B$. cinerea (Saligkarias et al. 2002), whereas the cell-wall degrading enzymes produced by Pichia guilliermondii Wick. have proven effective against Colletotrichum capsici (Syd. \& P. Syd.) E.J. Butler \& Bisby (Chanchaichaovivat et al. 2008) and B. cinerea (Zhang et al. 2011). No research investigated a parasitic relationship between A. pullulans and Fusarium pathogens. Antibiosis and hyperparasitism between the species and pathogenic fungi could be used to inhibit the growth and development of the latter on winter wheat kernels, and to reduce mycotoxin contamination of wheat grain.

Fusarium head blight (FHB), one of the most devastating diseases of common wheat (Triticum aestivum L.), is especially prevalent in warm and humid climates. The disease is caused by more than ten different species belonging to the genus Fusarium, mostly Fusarium graminearum Schwabe and Fusarium culmorum (W.G. Sm.) Sacc (Parry et al. 1995). In Eastern Europe, F. culmorum is the main causal agent of FHB (Jackowiak et al. 2005; Wiwart et al. 2011). In some years the predominant fungal pathogen on wheat grain is Fusarium poae (Peck) Wollenw. but this species exhibits low pathogenicity, and it usually does not reduce wheat yields (Vogelgsang et al. 2008; Wachowska et al. 2013). Fusarium langsethiae Torp \& Nirenberg, which had not been reported from Eastern Europe in the past, has also recently been isolated from wheat (Eukanowski and Sadowski 2008). In Finland the predominant species was Fusarium avenaceum (Fr.) Sacc. (91\%), which was isolated from all samples and some cases the wheat kernels were infected with more than one species (Logrieco et al. 2002). The above is indicative of dynamic changes in the composition and development of Fusarium species, related to weather conditions, geographical region, and cultivation practices (Edwards 2004). F. culmorum enters the host plant through the penetration of the hyphae into the tissue and secretion of starch-degrading enzymes (Jackowiak et al. 2005). In addition, trichothecene biosynthesis is induced in the infection structures of $F$. culmorum. Trichothecenes are able to bind to the $60 \mathrm{~S}$ ribosomal subunit of eukaryotes, which leads to the inhibition of protein synthesis and induction of apoptosis (Boenisch and Schäfer 2011). Mycotoxins increase the virulence of Fusarium pathogens against cereal plants, and pose a significant health risk for humans and animals. Currently, field application of various chemical fungicides is the primary strategy to control these harmful and mycotoxigenic pathogens on maize and on wheat (De Curtis et al. 2011; Haidukowski et al. 2005). Reducing mycotoxin contamination of winter wheat grain below the maximum permissible levels in an important consideration, especially in organic wheat production where the use of fungicides is limited. Previous research has focused on breeding of wheat cultivars of different species with increased resistance to fungal infections (Wiwart et al. 2011), whereas very few studies have focused on possibility of using yeasts for biological control of Fusarium diseases (Zhang et al. 2007). The aim of this study was to determine the effectiveness of $A$. pullulans in reducing the severity of winter wheat 
spikes infection caused by $F$. culmorum, and to analyze the interactions between $A$. pullulans and $F$. culmorum on winter wheat grain.

\section{Materials and methods}

Plant growth in the greenhouse

In September, in the growing seasons of 2009/2010, 2010/2011 and 2011/2012, winter wheat seeds of cv. Bogatka (obtained from breeding company Danko, Choryń, Poland) were placed in pots with a diameter of $30 \mathrm{~cm}$ using the typical brown soil formed from clay and sandy loam (World Reference Base for Soil Resources 1998). The soil's pH was equal to 6.5 , the carbon content reached a level of $1.05 \%$ and the nitrogen $0.08 \%$. In the biological control trials, wheat kernels were covered with a cell suspension of $A$. pullulans Ap1 obtained from winter wheat grain by immersing them for five minutes in a suspension with the density of $1 \times 10^{8}$ cells per $\mathrm{ml}$ of sterile water. In November, the plants were transferred in soil, in the field for vernalization. In April, the plants were transferred to the greenhouse. Throughout the growing season, the plants were watered every other day. At the tillering stage $(\mathrm{BBCH} 29)$ (Weber and Bleiholder 1990), the stem elongation stage (first node, BBCH $31)$ and the flag leaf stage (BBCH 39) to each pot were applied two grams of NPK fertilizer [Azofoska, INCO, Poland, $1(\mathrm{~N})$ : $\left.0.5\left(\mathrm{P}_{2} \mathrm{O}_{5}\right): 1.4\left(\mathrm{~K}_{2} \mathrm{O}\right)\right]$. During the growing season, the biocontrol agent was applied at the stem elongation (first node) stage (BBCH 31), and twice at the beginning and end of heading (BBCH 51, $\mathrm{BBCH} 59$ ) and for the third time at the full flowering stage (BBCH 65). The greenhouse temperature was maintained at $24-28{ }^{\circ} \mathrm{C}$. During flowering $(\mathrm{BBCH}$ 65-69), wheat spikes were inoculated with $F$. culmorum. A pot experiment was performed in four replications each consisting of 20 plants.

Biological protection of wheat plants during the growing season

Wheat spikes were protected against fungal pathogens with an A. pullulans Ap 1 isolate (Wachowska et al. 2013). Four-day-old colony forming units (CFU) of $A$. pullulans were washed off from the surface of PDA medium (Merck) with a sterile water. Wheat spikes were sprayed with the resulting suspension with the density of $2 \times 10^{8}$ cells in $1 \mathrm{ml}, 6 \mathrm{ml}$ per pot. The biocontrol agent was applied four times during the growing season, at the first node stage (BBCH 31), at the beginning and end of heading $(\mathrm{BBCH} 51, \mathrm{BBCH}$ $59)$ and at the full flowering stage (BBCH 65). The control group comprised plants grown from seeds surface disinfected with a $1 \%$ sodium hypochlorite solution, which were sprayed with water four times, at the stem elongation (first node) stage (BBCH 31), at the beginning and end of heading $(\mathrm{BBCH} 51, \mathrm{BBCH}$ $59)$ and at the full flowering stage (BBCH 65).

\section{Inoculation of wheat plants with F. culmorum}

The F. culmorum Fc 38 isolate obtained from winter wheat grain was characterized by high virulence, as previously explored against winter wheat seedlings (Wachowska et al. 2013). The conidia of $F$. culmorum were washed off with an inoculation loop, using sterile water, from 14-day-old colonies grown on PDA medium (Merck) in Petri dishes, at $24{ }^{\circ} \mathrm{C}$. The resulting inoculum suspension, with the density of $2 \times 10^{4}$ conidia $\mathrm{ml}^{-1}$ water, was applied onto winter wheat spikes by using two methods. The first method was employed in the growing seasons of 2009/2010 and 2010/2011. The conidial suspension was sprayed onto all spikes, at $6 \mathrm{ml}$ per pot, at the full flowering stage (BBCH 65). Inoculated spikes showed no visible symptoms of FHB. The second method was used in the growing seasons of 2010/2011 and 2011/2012. The conidial suspension was applied to two spikes per pot, at $0.3 \mathrm{ml}$ per spike, by spraying, at the beginning of flowering (BBCH 61). Inoculated spikes were covered with plastic bags, which were removed seven days after inoculation, when visible signs of infection were observed.

Microbiological analysis of winter wheat kernels by scanning electron microscopy (SEM)

Kernel samples were collected at the fully ripe stage (BBCH 89). After fixation (2.5\% glutaraldehyde, $4{ }^{\circ} \mathrm{C}$ ) and dehydration, wheat kernels were subjected to critical-point drying (CDP 030, BALTEC), mounted, and coated with gold (Fine Coater, JCF- 
1200, JEOL, Japan). The samples were analyzed by SEM (JSM-5310LV, JEOL, Japan), at 10-15 kV.

Evaluation of winter wheat yield and mycological analysis of wheat kernels

The spikes harvested at the fully ripening stage (BBCH 92) were threshed, the kernels were weighed and subjected to mycological analysis. Yeasts and filamentous fungi were isolated from wheat grain without visible disease symptoms, and from grain damaged by $F$. culmorum. In order to wash off epiphytes from wheat kernels, random grain samples of $10 \mathrm{~g}$ each were placed in $250 \mathrm{ml}$ flasks containing $90 \mathrm{ml}$ sterile water, and were shaken for $30 \mathrm{~min}$ (180 rpm) using a laboratory shaker (358-S, Elpin + , Poland). Microbial suspensions were transferred onto Petri dishes ( $9 \mathrm{~cm}$ diameter, $0.1 \mathrm{ml}$ in volume Margomed, Poland). Martin's medium (Martin 1950) warmed to $42{ }^{\circ} \mathrm{C}$ was poured into the dishes. The experiment was performed in four replicates. The number of fungal colonies in plates was counted. The colonies of filamentous fungi were identified to the genus or species level based on their sporulation characteristics (Ellis 1971; Leslie et al. 2006) under a light microscope (Nikon E 200, Japan).

\section{Evaluation of FHB severity}

Winter wheat spikes were rated for FHB severity at the hard dough stage (BBCH 87). The infection rates of all spikes were estimated as an average percentage of affected surface area according to Bulletin (1998).

\section{Statistical analysis}

The data regarding the abundance of microbial communities were log transformed $(\mathrm{CFU}+1)$. Averaged number of cells and cell aggregates of $A$. pullulans per one kernel was given. The significance of differences between mean values was estimated by two-way ANOVA, and the significance of differences between the average population sizes of yeasts, filamentous fungi, cells and cell aggregates of $A$. pullulans on wheat kernels was estimated by the multiple Student-Newman-Keuls (SNK) test using Statistica 10.0 software (StatSoft 2011).

\section{Results}

Abundance of yeasts and filamentous fungi on winter wheat kernels

The method of spike inoculation with $F$. culmorum had a significant effect on the growth of yeast populations (Table 1). The abundance of epiphytic yeasts was by almost $34 \%$ lower on wheat kernels collected from inoculated spikes covered with plastic bags, which showed visible symptoms of FHB, in comparison with biologically protected and noninoculated kernels. Yeast counts were reduced by $16.13 \%$ on wheat kernels inoculated by the first method and showing no signs of infection. The abundance of epiphytic yeasts on kernels harvested from biologically protected and non-inoculated wheat plants was by $56.7 \%$ higher, compared with the control treatment.

In the control treatment, numerous colonies of filamentous fungi were washed off from the surface of wheat kernels, mostly saprotrophic species belonging to the genera Acremonium, Penicillium and Cladosporium (mostly Cladosporium herbarum (Pers.) Link and Cladosporium cladosporioides (Fresen.) G.A. de Vries). Fungi belonging to the genus Penicillium were not isolated from wheat kernels collected from spikes inoculated with $F$. culmorum by the method 1 (Table 1 ). On kernels from spikes inoculated by the method 2, the community of the above saprotrophs was reduced by $20.17 \%$, compared with the control. In comparison with control, the inoculation method 1 contributed to a decrease in the abundance of Acremonium and Cladosporium species, by 39.4 and $32.86 \%$, respectively, and to an increase in the population size of Alternaria alternata (Fr.) Keissl. and F. poae, 3.7-fold and by $37.68 \%$, respectively. No colonies of $F$. culmorum were isolated from kernels derived from inoculated spikes by the method 1. A high moisture content of spikes after inoculation with the pathogen by the method 2 supported the growth of species from genera Acremonium and Cladosporium. Few colonies of F. culmorum were isolated from wheat kernels from heads inoculated by the method 2. The biocontrol agent increased the abundance of Acremonium species and $A$. alternata on wheat kernels, by 43.43 and $274.07 \%$, respectively, and it reduced the growth of Penicillium species by $8.83 \%$, compared with the untreated kernels. 
Distribution of A. pullulans on wheat kernels from spikes inoculated with $F$. culmorum.

The hyphae of $F$. culmorum were sporadically observed on kernels collected from heads inoculated by the method 1 and showed no symptoms of FHB, which supported the rapid development of A. pullulans. Individual cells and cell aggregates of $A$. pullulans were unevenly distributed on wheat kernels. In the control, they were found on the surface, in the brush and, less frequently, in the crease of kernels (Table 2). In some cases, the homeostasis was disturbed by the application of A. pullulans and $F$. culmorum to wheat spikes. Inoculation with $F$. culmorum by the method 1 did not cause changes in the distribution and abundance of A. pullulans on the surface of wheat kernels observed under scanning electron microscope (Table 2). After the application of F. culmorum abundance of single-celled A. pullulans in the crease of kernels was almost ninefold higher than in the control (Table 2). The application of the pathogen reduced the number of individual cells of A. pullulans in the brush of kernels by $25.1 \%$, in comparison with control. After the application of the yeast $A$. pullulans its cells were found mostly in the crease of kernels, and their abundance in the crease was more than fourfold higher, compared with the control treatment. The biocontrol agent and the pathogen reduced the number of aggregates of $A$. pullulans cells on the surface and in the brush of kernels, in comparison with control. The biocontrol agent contributed to a significant increase in the number of cell aggregates of $A$. pullulans in the crease of kernels. Aureobasidium pullulans cells were sporadically observed on wheat kernels after inoculation with $F$. culmorum by the method 2, and in most cases they were attached to the numerous hyphae of the pathogen.

\section{Observations under SEM}

Symptoms of $F$. culmorum infection were analyzed only on wheat spikes inoculated by the method 2 by using plastic bags. Numerous hyphae of $F$. culmorum were observed on the lateral sides, in the crease and in the brush of kernels showing symptoms of infection (Fig. 1a). On strongly damaged kernels, numerous hyphae were noted even inside the starchy endosperm 
Table 2 Distribution of cells and cell aggregates of A. pullulans $( \pm$ SE) on different parts of winter wheat kernels inoculated by the first method (spikes showing no symptoms of FHB)

\begin{tabular}{|c|c|c|c|c|c|c|}
\hline \multirow[t]{2}{*}{ Treatment } & \multicolumn{3}{|c|}{ Average number of individual cells } & \multicolumn{3}{|c|}{ Average number of cell aggregates } \\
\hline & Kernel surface & Crease & Brush & Kernel surface & Crease & Brush \\
\hline Non-treated control & $31.00( \pm 2.00)^{\mathrm{c}}$ & $1.50( \pm 0.96)^{\mathrm{a}}$ & $21.25( \pm 0.05)^{\mathrm{bc}}$ & $1.50( \pm 0.59)^{\mathrm{z}}$ & $0.00( \pm 0.00)^{\mathrm{x}}$ & $1.25( \pm 0.63)^{\mathrm{yz}}$ \\
\hline $\begin{array}{l}\text { Inoculation with } F \text {. } \\
\text { culmorum method } 1\end{array}$ & $28.00( \pm 6.74)^{\mathrm{c}}$ & $13.33( \pm 2.96)^{\mathrm{abc}}$ & $15.83( \pm 4.85)^{\mathrm{abc}}$ & $1.33( \pm 0.99)^{\mathrm{z}}$ & $0.33( \pm 0.21)^{x y}$ & $0.00( \pm 0.00)^{\mathrm{x}}$ \\
\hline A. pullulans & $18.06( \pm 1.31)^{\mathrm{abc}}$ & $6.19( \pm 1.66)^{\mathrm{ab}}$ & $14.56( \pm 3.66)^{\mathrm{c}}$ & $0.50( \pm 0.50)^{\mathrm{xy}}$ & $0.88( \pm 0.69)^{\mathrm{y}}$ & $0.63( \pm 0.24)^{x y}$ \\
\hline
\end{tabular}

Means signed by the same letter differ not significantly according to SNK test at $p \leq 0.05$ (a-c for average number of individual cells, $\mathrm{x}-\mathrm{z}$ for average number of cell aggregates). F-values for average number of individual cells: $\mathrm{F}_{(2,27)}=23.53, p<0.001$ (for a part of kernel factor 1), $\mathrm{F}_{(2,27)}=3.21, p=0.64$ (for a treatment factor 2), $\mathrm{F}_{(4,27)}=3.09, p=0.042$ (for interaction). $\mathrm{F}$-values for average number of cell aggregates: $\mathrm{F}_{(2,27)}=3.66, p<0.046$ (for factor 1$), \mathrm{F}_{(2,27)}=0.69, p=0.511$ (for factor 2 ), $\mathrm{F}_{(4,27)}=3.23$, $p=0.036$ ) (for interaction)

with starch grains whose diameter varied from several to over ten $\mu \mathrm{m}$, with visible pores characterized by concentric, usually bilayer, structure caused by enzymatic degradation (Fig. 1b, dotted arrows). Microscopic images revealed numerous infection structures (Fig. 2), including infection cushions (ic) with an average diameter of $25 \mu \mathrm{m}$ (Fig. 2a), lobate appressoria (la), 4.5-6 $\mu \mathrm{m}$ in diameter (Fig. 2a, b, d, and runner hyphae (rh), $1.7 \mu \mathrm{m}$ in diameter (Fig. 3a, b). Foot structures (fs) with a diameter of 4-6 $\mu \mathrm{m}$, visible on the electronograms, were often located close to the infection cushions (Fig. 2c). After the removal of the infection structures of $F$. culmorum, penetration pores (pp) with a diameter of $4.5-10 \mu \mathrm{m}$, were noted in the outer layer of wheat kernels (Fig. 2d).

Yeast cells were sporadically observed on kernels inoculated with $F$. culmorum by the method 2 , and in most cases they were attached to the hyphae of $F$. culmorum (Fig. 3a, dotted arrow). Numerous hyphae covering the surface of kernels included degraded hyphae of $F$. culmorum, with a strongly undulating surface (Fig. 3b dashed arrow).

Fusarium head blight

Wheat spikes sprayed with the inoculum in the first two growing seasons showed no symptoms of FHB. Spikes inoculated by the method 2 were strongly damaged, with $91.25 \%$ spike area affected on average (Fig. 4). The effectiveness of biological control in spikes inoculated by the method 2 was estimated at $21.67 \%$. Spikes inoculated with $F$. culmorum by the method 1 were characterized by lower filling rates, and
1000 kernel weight was by $46.22 \%$ lower, compared with non-inoculated control (Fig. 4). 1000 kernel weight was four-fold lower in spikes inoculated by the method 2 than in the case of control spikes. Biological control improved grain filling by $5.02 \%$, in comparison with unprotected plants.

\section{Discussion}

The fungal communities isolated from the surface of wheat kernels were typical of the analyzed ecological niche (Laca et al. 2006; Berghofer et al. 2003), and they were dominated by yeasts, followed by filamentous fungi of the genera Acremonium and Penicillium whose abundance decreased after spike inoculation with $F$. culmorum. In treatments with biological control, yeast communities were dominated by colonies of A. pullulans whose characteristics have been described previously (Liu et al. 2009; Gniewosz and Duszkiewicz-Reinhard 2008). In our study the high population densities of yeasts on wheat kernels protected them against infection caused by F. culmorum. The effectiveness of biological control applied in our study was lower than in a greenhouse test performed by Zhang et al. (2007) who demonstrated that an isolate of Cryptococcus flavescens reduced the severity of spike infection caused by $F$. graminearum by $82.2 \%$. In a greenhouse experiment carried out by Schisler et al. (2006), the A. pullulans AS 55.2 isolate reduced the severity of FHB caused by Gibberella zeae (Schwein.) Petch by $84 \%$. According to the cited authors, the probable mechanism of action of the analyzed isolate involves the biodegradation of 

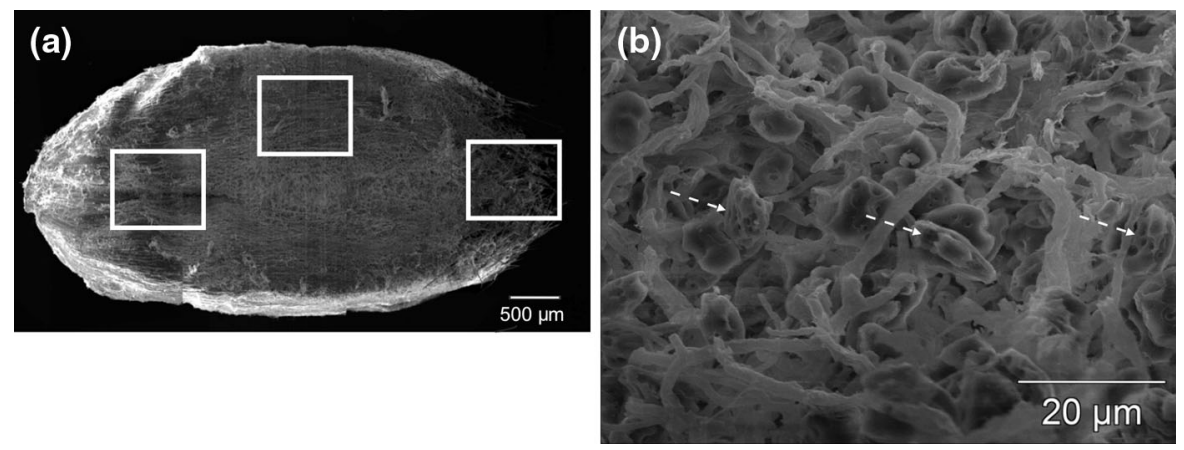

Fig. 1 The areas observed on winter wheat kernels (a), damage of starch granules as an effect of the amylolytic enzymes produced by F. culmorum (b, dashed arrows)
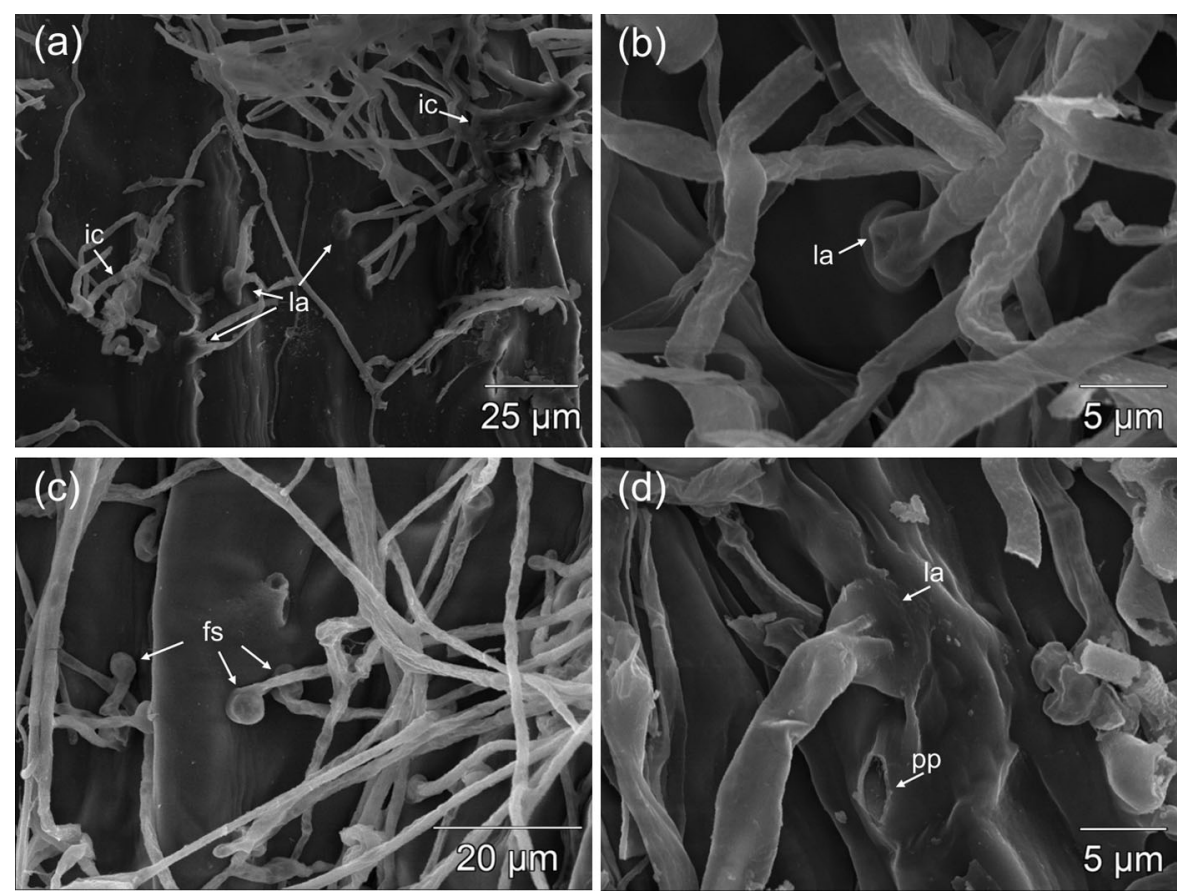

Fig. 2 Infection structures of $F$. culmorum on winter wheat kernels. ic—infection cushion (a), la-lobate appressorium (b, d), fs-foot structures $(\mathbf{c}), \mathrm{pp}$ - penetration pores $(\mathbf{d})$

choline, a compound that stimulates the growth of $G$. zeae (Engle et al. 2004). In a field trial conducted by Khan et al. (2004), the majority of yeast isolates, including members of the genus Cryptococcus, suppressed FHB caused by G. zeae, but biocontrol efficacy differed depending on wheat cultivar and weather conditions.

In our study the inoculation with $F$. culmorum considerably reduces grain filling rates, by 46.2 and $75 \%$, by using respectively the first or the second method in comparison with the control treatment. In a field study by Schade-Schütze et al. (2000), inoculation of wheat spikes with $F$. culmorum reduced 1000 kernel weight by 14-61\%. Korn et al. (2011) demonstrated that the $F$. culmorum isolate was characterized by higher aggressiveness in wheat heads than $F$. graminearum isolates, and that its aggressiveness only partially resulted from the production of mycotoxins such as deoxynivalenol, nivalenol and zearalenone. In our study, higher grain filling rates 

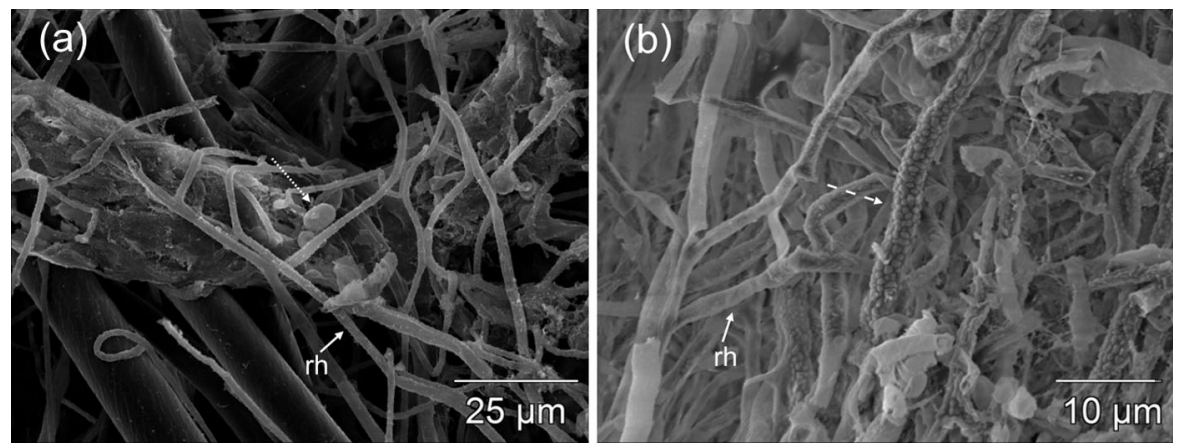

Fig. 3 Yeast cells attached to the hyphae of F. culmorum (a, dotted arrow), degraded hyphae of F. culmorum (b, dashed arrow). rhrunner hyphae

(a)

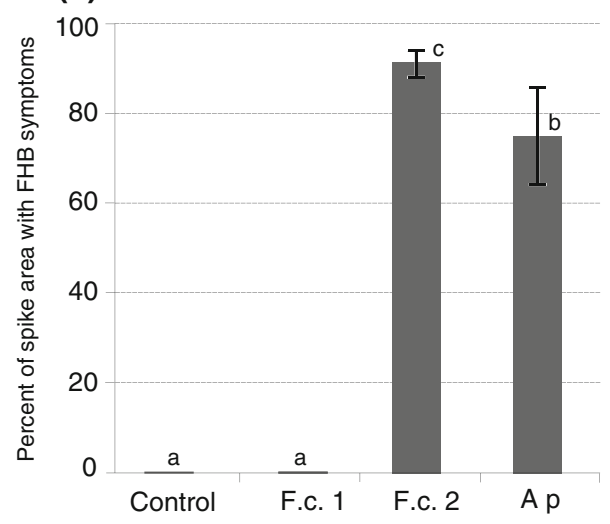

Fig. 4 Severity of FHB symptoms (a) and 1000 kernel weight (b) in conditions of experiment. F.c.1-inoculation with $F$. culmorum method 1, F.c.2-inoculation with $F$. culmorum method 2, Ap-inoculation with A. pullulans $\left(\mathrm{F}_{(3,9)}=36.10\right.$, $p<0.0001$ for severity of $\mathrm{FHB}$ symptoms, $\mathrm{F}_{(3,9)}=17.24$,

were noted for winter wheat spikes non-inoculated with $F$. culmorum and protected with A. pullulans, compared with untreated spikes. Our results corroborate the earlier findings of Khan et al. (2004) who reported that the wheat cultivar Pioneer grown in plots treated with Cryptococcus isolates was characterized by higher 1000 kernel weight.

The A. pullulans isolate used to protect winter wheat spikes against $F$. culmorum in our greenhouse experiment suppressed this pathogen. Degraded hyphae of $F$. culmorum were observed in few SEM images, and the damage was most likely caused by chitinolytic enzymes. The ability of A. pullulans to produce such enzymes has also been reported by other

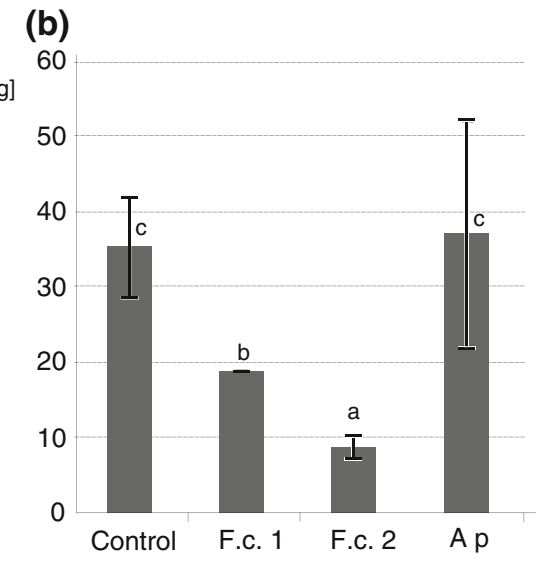

$p=0.00045$ for 1000 kernel weight). Values signed by the same letter differ not significantly according to SNK test at $p<0.01$ (separately for FHB symptoms and 1000 kernel weight). The error bars correspond to SE

authors (Govinda Rajulu et al. 2011). In a study by Calistru et al. (1997), SEM images revealed degradation of hyphae of Aspergillus flavus Link treated with culture filtrates of Trichoderma harzianum Rifai. Minaxi and Saxena (2010) observed that bacteria Pseudomonas BAM-4 caused hyphal deformities such as fragmentation, lysis and swelling of mycelia of Fusarium oxysporum Schltdl. The changes noted by the cited authors correspond to those observed on the surface of the hyphae of $F$. culmorum in the presented experiment. The adhesion of yeast cells to the pathogen's hyphae, noted in our study, has been described previously (Hashem and Alamri 2009; Zhang et al. 2011; Arras et al. 1999). 
We have observed that very few CFU of $F$. culmorum were isolated from severely infected wheat kernels covered with the pathogen's hyphae. This was most likely due to the presence of numerous infection structures that firmly attached the pathogen's hyphae to the surface of kernels, accompanied by very few conidia. The infection structures of $F$. culmorum observed in our study were similar to those described by Boenisch and Schäfer (2011) who investigated the infection process of $F$. graminearum. Numerous SEM images show lobate appressoria and infection cushions of F. culmorum-multicellular structures formed by irregularly shaped hyphae. In most cases, the hyphae of $F$. culmorum colonized kernel tissue by immediate penetration (infection hyphae), and less frequently they entered though natural openings. The method 1 of spike inoculation resulted in the formation of short infection hyphae, described also by Kang and $\mathrm{Bu}-$ chenauer (2000) who analyzed the infection structures of $F$. culmorum. The above authors observed mycelium with infection hyphae on the top of the ovary. Such structures were also frequently encountered in our study. After their removal, SEM images revealed characteristic penetration pores in the outer kernel layer, which suggests that the pathogen produced enzymes capable to degrade the host's tissues. Observed starch granules were also degraded by the enzymes produced by $F$. culmorum. The image of degradation of starch granules observed in our experiment is consistent with that described by Jackowiak et al. (2005)-multilayer pores were noted on the edges and in the center of big (type A) starch grains.

The isolate of $F$. culmorum used in our study exhibited high aggressiveness on winter wheat under greenhouse conditions, but only when inoculated spikes were covered with plastic bags and placed in a moisture chamber. The analyzed isolate formed numerous infection structures, penetrated into the interior of wheat and manifested high enzymatic activity toward the epidermis and starch granules in the kernel. The survival rates of A. pullulans on kernels were very high, including in pathogen-inoculated wheat plants, but inoculation shifted the location of its cells and cell aggregates from the brush to the crease of kernels. A. pullulans cells firmly adhered to $F$. culmorum cells, and in some cases they damaged the pathogen's hyphae. Autochthonous communities of filamentous fungi of the genera Acremonium and
Penicillium developed at a slower rate after inoculation with the pathogen. The growth of Acremonium species was suppressed following spike inoculation by the first method, and the growth of Penicilium species was inhibited after spike inoculation by the second method.

Acknowledgments The work was cofinanced by the National Science Center, Poland, Project No. N N 310116638.

Open Access This article is distributed under the terms of the Creative Commons Attribution License which permits any use, distribution, and reproduction in any medium, provided the original author(s) and the source are credited.

\section{References}

Arras G, Nicolussi P, Ligios C (1999) Non-toxicity of some antifungal yeasts (Pichia guilliermondii, Rhodotorula glutinis and Candida oleophila) in laboratory animals. Ann Microbiol Enzim 49:125-131

Berghofer LK, Hocking AD, Miskelly D, Jansson E (2003) Microbiology of wheat and flour milling in Australia. Int J Food Microbiol 85:137-149

Boenisch MJ, Schäfer W (2011) Fusarium graminearum forms mycotoxin producing infection structures on wheat. BMC Plant Biol 11:110-123

Calistru C, McLean M, Berjak P (1997) In vitro studies on the potential for biological control of Aspergillus flavus and Fusarium moniliforme by Trichoderma species. Mycopathologia 139(2):115-121

Castoria R, de Curtis F, Lima G, Caputo L, Pacifico S, de Cicco V (2001) Aureobasidium pullulans (LS-30) an antagonist of postharvest pathogens of fruits: study on its modes of action. Postharvest Biol Technol 22:7-17

Chanchaichaovivat A, Panijpan B, Ruenwongsa P (2008) Putative modes of action of Pichia guilliermondii strain R13 in controlling chilli anthracnose after harvest. Biol Control 47(2):207-215

De Curtis F, De Cicco V, Haidukowski M, Pascale M, Somma S, Moretti A (2011) Effects of agrochemical treatments on the occurrence of Fusarium ear rot and fumonisin contamination of maize in Southern Italy. Field Crops Res 123:161-169

De Curtis F, Lima G, De Cicco V (2012a) Efficacy of biocontrol yeasts combined with calcium silicate or sulphur for controlling durum wheat powdery mildew and increasing grain yield components. Field Crops Res 134:36-46

De Curtis F, de Felice DV, Ianiri G, De Cicco V, Castoria R (2012b) Environmental factors affect the activity of biocontrol agents against ochratoxigenic Aspergillus carbonarius on wine grape. Intern J Food Microbiol 159:17-24

De Felice DV, Solfrizzo M, De Curtis F, Visconti A, Castoria R (2008) Decrease of ochratoxin A contamination in wine grapes by strains of Aureobasidium pullulans. Phytopa- 
thology 98(12):1261-1270

Donot F, Fontana A, Baccou JC, Schorr-Galindo S (2012) Microbial exopolysaccharides: main examples of synthesis, excretion, genetics and extraction. Carbohyd Polym 87(2):952-962

Edwards SG (2004) Influence of agricultural practices on Fusarium infection of cereals and subsequent contamination of grain by trichothecene mycotoxins. Toxicol Lett 153:29-35

Ellis MB (1971) Dematiaceous hyphomycetes. The Eastern Press, London, UK

Engle JS, Lipps PE, Graham TL, Boehm MJ (2004) Effects of choline, betaine and wheat floral extracts on growth of Fusarium graminearum. Plant Dis 88:175-180

EPPO (1998) European and mediterranean plant protection organization Guideline for the efficacy evaluation of fungicides, foliar diseases of cereals. Bulletin OEPP/EPPO 28: 279-290

Gniewosz M, Duszkiewicz-Reinhard W (2008) Comparative studies on pullulan synthesis, melanin synthesis and morphology of white mutant Aureobasidium pullulans B-1 and parent strain A.p.-3. Carbohyd Polym 72:431-438

Govinda Rajulu MB, Thirunavukkarasu N, Suryanarayanan TS, Ravishankar JP, El Gueddari NE, Bruno M, Moerschbacher BM (2011) Chitinolytic enzymes from endophytic fungi. Fungal Divers 47:43-53

Grube M, Schmid F, Berg G (2011) Black fungi and associated bacterial communities in the phyllosphere of grapevine. Fungal Biol 115(10):978-986

Haidukowski M, Pascale M, Perrone G, Pancaldi D, Campagna C, Visconti A (2005) Effect of fungicides on the development of Fusarium head blight, yield and deoxynivalenol accumulation in wheat inoculated under field conditions with Fusarium graminearum and Fusarium culmorum. J Sci Food Agric 85:191-198

Hashem M, Alamri S (2009) The biocontrol of postharvest disease (Botryodiplodia theobromae) of guava (Psidium guajava L.) by the application of yeast strains. Postharvest Biol Technol 53:123-130

Ippolito A, El Ghaouth AL, Wilson CL, Wisniewski M (2000) Control of postharvest decay of apple fruit by Aureobasidium pullulans and induction of defense responses. Postharvest Biol Technol 19:265-272

Jackowiak H, Packa D, Wiwart M, Perkowski J (2005) Scanning electron microscopy of Fusarium damaged kernels of spring wheat. Int J Food Microbiol 98(2):113-123

Kang Z, Buchenauer H (2000) Ultrastructural and cytochemical studies on the infection of wheat spikes by Fusarium culmorum as well as on degradation of cell wall components and localization of mycotoxins in the host tissue. Mycotoxin Res 16(1):1-5

Khan NI, Schisler DA, Boehm MJ, Lipps PE, Slininger PJ (2004) Field testing of antagonists of Fusarium head blight incited by Gibberella zeae. Biol Control 29:245-255

Korn U, Müller T, Ulrich A, Müller ME (2011) Impact of aggressiveness of Fusarium graminearum and F. culmorum isolates on yield parameters and mycotoxin production in wheat. Mycotoxin Res 27(3):195-206

Kuan-Chen C, Demirci A, Catchmark JM (2011) Pullulan: biosynthesis, production, and applications. Appl Microbiol Biot 92(1):29-44
Laca A, Mousia Z, Diaz M, Webb C, Pandiella SS (2006) Distribution of microbial contamination within cereal grains. J Food Eng 72:332-338

Leite RSR, Alves-Prado HF, Cabral H, Pagnocca FC, Gomes E, Da-Silva R (2008) Production and characteristics comparison of crude $\beta$-glucosidases produced by microorganisms Thermoascus aurantiacus e Aureobasidium pullulans in agricultural wastes. Enzyme Microb Technol 43(6):391-395

Leslie JF, Summerrell BA, Bullock S (2006) The Fusarium laboratory manual. Blackwell, Oxford, UK

Li HF, Chi Z, Wang X, Ma C (2007) Amylase production by the marine yeast $A$. pullulans N13d. J Ocean Univ China 6(1):60-65

Lima G, Ippolito A, Nigro F, Salerno M (1997) Effectiveness of Aureobasidium pullulans and Candida oleophila against postharvest strawberry rots. Postharvest Biol Technol 10(2):169-178

Liu J, Liu Z, Chi Z, Zhang L, Zhang D (2009) Intraspecific diversity of Aureobasidium pullulans strains from different marine environments. J Ocean Univ China 8(3):241-246

Logrieco A, Rizzo A, Ferracane R, Ritieni A (2002) Occurrence of beauvericin and enniatins in wheat affected by Fusarium avenaceum head blight. Appl Environ Microbiol 68(1):82-85

Łukanowski A, Sadowski C (2008) Fusarium langsethiae on kernels of winter wheat in Poland-occurrence and mycotoxigenic abilities. Cereal Res Commun 36:453-457

Manitchotpisit P, Skory CD, Leathers TD, Lotrakul P, Eveleigh DE, Prasongsuk S, Punnapayak H (2011) $\alpha$-Amylase activity during pullulan production and $\alpha$-amylase gene analyses of Aureobasidium pullulans. J Ind Microbiol Biot 38:1211-1218

Mari M, Martini C, Guidarelli M, Neri F (2012) Postharvest biocontrol of Monilinia laxa, Monilinia fructicola and Monilinia fructigena on stone fruit by two Aureobasidium pullulans strains. Biol Control 60(2):132-140

Martin JP (1950) Use of acid, rose Bengal and streptomycin in the plate method for estimating soil fungi. Soil Sci 38:215-220

Minaxi, Saxena J (2010) Disease suppression and crop improvement in moong beans (Vigna radiata) through Pseudomonas and Burkholderia strains isolated from semi arid region of Rajasthan, India. Biol Control 55:799-810

Mounir R, Durieux A, Bodo E, Allard C, Simon JP, Achbani EH, El-Jaafari S, Douira A, Jijakli MH (2007) Production, formulation and antagonistic activity of the biocontrol likeyeast Aureobasidium pullulans against Penicillium expansum. Biotechnol Lett 29(4):553-559

Olstrope M, Borling J, Schnurer J, Passoth V (2010) Pichia anomala yeast improves feed hygiene during storage of moist crimped barley grain under Swedish farm conditions. Anim Feed Sci Technol 156:37-46

Parry DW, Jenkinson P, McLeod L (1995) Fusarium ear blight (scab) in small grain cereals: a review. Plant Pathol 44(2):207-238

Prasongsuk S, Sullivan RF, Kuhirun M, Eveleigh DE, Punnapayak H (2005) Thailand habitats as sources of pullulanproducing strains of Aureobasidium pullulans. World J Microb Biot 21:393-398

Saligkarias ID, Gravanis FT, Epton HAS (2002) Biological control of Botrytis cinerea on tomato plants by the use of 
epiphytic yeasts Candida guilliermondii strains 101 and US 7 and Candida oleophila strain I-182: II-a study on mode of action. Biol Control 25(2):151-161

Schade-Schütze A, Muthomi J, Oerke E, Dehne H (2000) Yield reduction and mycotoxin contamination of wheat due to Fusarium culmorum. Mycotoxin Res 16(Suppl 1):34-37

Schisler DA, Khan NI, Boehm MJ, Lipps PE, Slininger PJ, Zhang S (2006) Selection and evaluation of the potential of choline-metabolizing microbial strains to reduce Fusarium head blight. Biol Control 39:497-506

StatSoft Inc. (2011) STATISTICA (data analysis software system), version 10. http://www.statsoft.com. Accessed 9 July 2014

Stratilová E, Dzúrová M, Breierová E, Omelková J (2006) Production and biochemical characterization of polygalacturonases produced by Aureobasidium pullulans from forest soil. Ann Microbiol 56(1):35-40

Tournas VH, Uppal Memon S (2009) Internal contamination and spoilage of harvested apples by patulin-producing and other toxigenic fungi. Int J Food Microbiol 133:206-209

Vogelgsang S, Sulyok M, Hecker A, Jenny-Ludwig E, Krska R, Schuhmacher R, Forrer HR (2008) Toxigenicity and pathogenicity of Fusarium poae and Fusarium avenaceum on wheat. Eur J Plant Pathol 122:265-276

Wachowska U, Kucharska K, Jędryczka M, Łobik N (2013) Microorganisms as biological control agents against Fusarium pathogens in winter wheat. Pol J Environ Stud 22(2):591-597

Weber E, Bleiholder H (1990) Erläuterungen zu den BBCHdezimal-codes für die entwicklungsstadien von mais, raps, faba-bohne, sonnenblume und erbse mit abbildungen. Gesunde Pflanz 42:308-321
Wiwart M, Perkowski J, Budzyński W, Suchowilska E, Buśko M, Matysiak A (2011) Concentrations of ergosterol and trichothecenes in the grains of three Triticum species. Czech J Food Sci 4:430-450

World Reference Base for Soil Resources (1998) Food and Agriculture Organization of the United Nations, Rome, Italy

Zalar P, Gostinčar C, de Hoog GS, Uršič V, Sudhadham M, Gunde-Cimerman N (2008) Redefinition of Aureobasidium pullulans and its varieties. Stud Mycol 61:21-38

Zhang S, Schisler DA, Boehm MJ, Slininger PJ (2007) Utilization of chemical inducers of resistance and Cryptococcus flavescens $\mathrm{OH} 182.9$ to reduce Fusarium head blight under greenhouse condition. Biol Control 42:308-315

Zhang S, Spadaro D, Garibaldi A, Gullino ML (2011) Potential biocontrol activity of a strain of Pichia guilliermondii against grey mold of apples and its possible modes of action. Biol Control 57:193-201

Urszula Wachowska is a phytopathologist and mycologist working at the Warmia and Mazury University in Olsztyn on the professor position. Her research field is the integrated and biological protection of cereals and some horticultural plants, mainly strawberries.

Katarzyna Głowacka is a plant cytophysiolgist working at the Department of Plant Physiology, Genetics and Biotechnology. She investigates mechanisms of plant responses to environmental stresses, mainly pathogens and heavy metals. 